\title{
Main stem bronchus surgery with pulmonary preservation
}

\author{
Mohsen Ibrahim, MD, PhD, and Cecilia Menna, MD
}

\footnotetext{
From the Division of Thoracic Surgery, Sant'Andrea Hospital, Faculty of Medicine and Psychology, Sapienza University of Rome, Rome, Italy.

Disclosures: Authors have nothing to disclose with regard to commercial support.

Received for publication March 14, 2017; accepted for publication March 17, 2017; available ahead of print April $12,2017$.

Address for reprints: Mohsen Ibrahim, MD, PhD, Division of Thoracic Surgery, Faculty of Medicine and Psychology, Sapienza University of Rome, Sant'Andrea Hospital, Via di Grottarossa 1035, 00189 Rome, Italy (E-mail: mohsen.ibrahim@uniroma1.it).

J Thorac Cardiovasc Surg 2017;154:373-4

$0022-5223 / \$ 36.00$

Copyright (C) 2017 by The American Association for Thoracic Surgery

http://dx.doi.org/10.1016/j.jtcvs.2017.03.064
}

Main stem bronchial sleeve resection is defined as the circumferential resection of the main stem bronchus. Resection of a main stem bronchus with pulmonary preservation is a therapeutic option when disease is limited to the main stem bronchus. Such resection of a main stem bronchus is often performed with sleeve lobectomy. Generally, for excision of lesions involving a single lobar bronchial orifice with extension into the main stem bronchus but sparing the other lobar bronchial orifices, a pulmonary lobectomy with sleeve resection of the main bronchus can be performed.

In 1947 Sir Clement Price Thomas in London first performed the procedure. ${ }^{1}$ A sleeve resection of the left interlobar carina may be carried out through a double-barreled anastomosis between the left main bronchus and the cut ends of the left upper and lower bronchi, as Caviezel and colleagues $^{2}$ are presenting in their article in this issue of the Journal. The reconstruction of the neolobar carina is technically demanding because of the close proximity of the apical segmental bronchi of the lower lobes and the lingular bronchus of the left superior lobe. The usual surgical access is a posterolateral or lateral thoracotomy (Figure 1). Caviezel and colleagues ${ }^{2}$ propose the use of an anterior thoracotomy, which could lead to technical difficulties as a result of incomplete interlobar fissures or the presence of an anatomic variant, such as a unique pulmonary vein.

All publications in the literature on this topic are case reports. ${ }^{1,4,5}$ The value of parenchyma-sparing resections has been emphasized for benign or low-grade malignant bronchial diseases. When the lesion is located distally and involves the origin of the lobar bronchi or is diagnosed as malignant tumors, the decision about which operation to perform is often unclear. Further prospective studies are therefore needed to generate data on long-term outcomes for the better evaluation of the necessity of sleeve resections with complete preservation of the lung parenchyma for the treatment of aggressive tumors.

It is well established ${ }^{1,3-5}$ that there is variability in oncologic outcomes of patients with thoracic neoplasms.

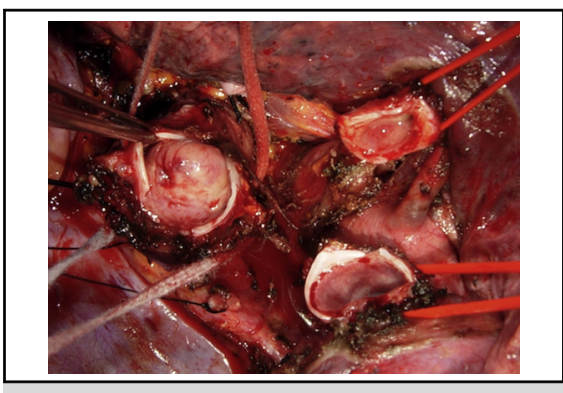

The right main, intermedius, and superior bronchus with the tumor at the bifurcation.

\section{Central Message}

Bronchial sleeve resection with total preservation of the lung parenchyma appears to be an adequate option for treating neoplasms arising from major bronchi in appropriately selected patients.

See Article page 370 .

Reported disease-free survival varies from 10 months to 14 years. For early-stage carcinoma, endoluminal interventions such as YAG laser or endobronchial stenting may be therapeutic options. None of these endoluminal therapies, however, can exactly address parenchymal margins, the depth of invasion, or the intraparenchymal nodal status. Bronchial sleeve resection with total preservation of the lung parenchyma therefore appears to be an adequate option for treating neoplasms arising from major bronchi in appropriately selected patients with resectable tumors growing within the bronchial wall.

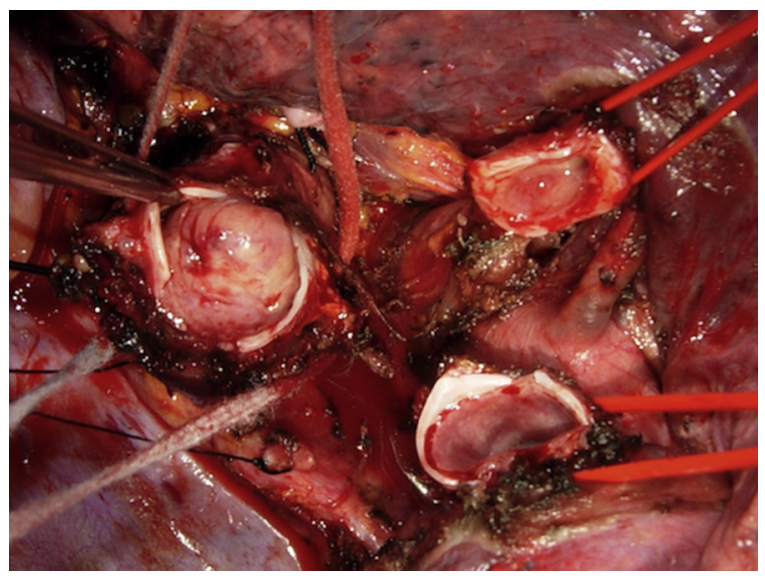

FIGURE 1. Interoperative photo shows the right main, intermedius, and superior bronchus, with the tumor at the bifurcation. 


\section{References}

1. Thomas CP. Conservative resection of the bronchial tree. J R Coll Surg Edinb. 1956;3:168-86

2. Caviezel C, Koersgen F, Weder W, Inci I. Left main bronchus sleeve resection with reconstruction of neolobar carina. J Thorac Cardiovasc Surg. 2017;154: $370-2$.

3. Maurizi G, Ibrahim M, Andreetti C, D'Andrilli A, Ciccone AM, Pomes LM, et al. Long-term results after resection of bronchial carcinoid tumour: evalu- ation of survival and prognostic factors. Interact Cardiovasc Thorac Surg. 2014;19:239-44.

4. Oliaro A, Casadio C, Ruffini E, Giobbe R, Pischedda F, Maggi G. Bronchial sleeve resection distal to the main bronchi with complete pulmonary preservation. Report on three successful cases. J. Cardiovasc Surg (Torino). 1994;35:157-60.

5. Ohta Y, Yachi T, Oda M, Sato H, Shimizu J, Watanabe Y, et al. Bronchial sleeve resection with complete preservation of the lung for carcinoma. Respiration. 2001;68:528-32. 